\title{
A 7 year old girl with anemia and massive hepatosplenomegaly
}

\author{
Mohammad Mizanur Rahman, Md. Mehedhi Hasan Shourov, Debashish Saha, Md. Abdul Ali Miah \\ and S. M. Motahar Hossain
}

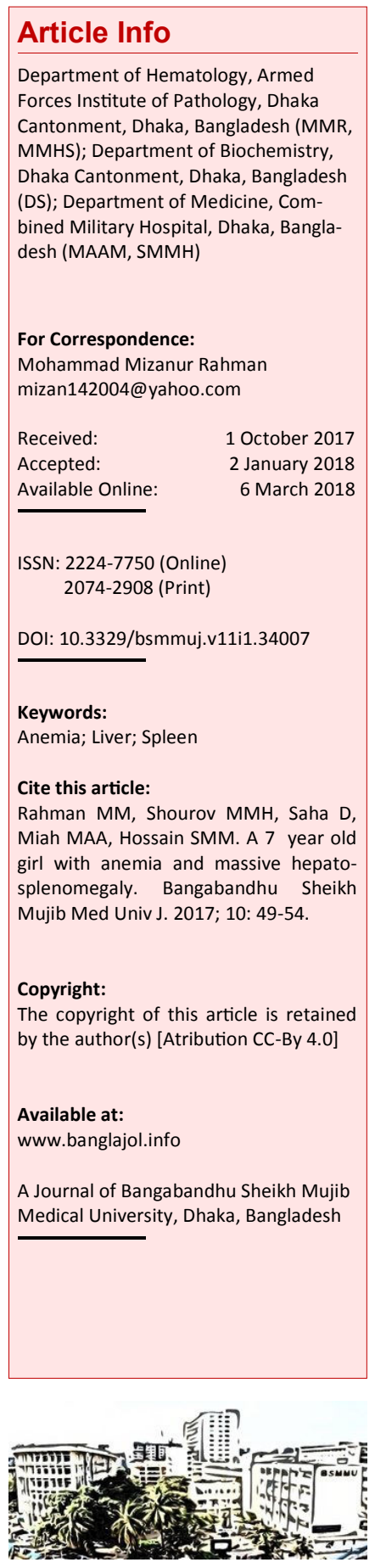

\section{Presentation of Case}

Dr. Md. Mehedhi Hasan Shourov: A 7 year old girl reported to the child outpatient department of a military hospital in Chittagong (South-East part of Bangladesh) Cantonment with the complaints of generalized weakness, loss of appetite, gradual distention of the abdomen and weight loss.

The child was reasonably well and performing all her daily activities at her own 1 year before. She was also going to the school regularly and was worried when her parents noticed the distension of her abdomen and reluctant to take food adequately. The child also developed weakness and witnessed weight loss. At that time, there was no history of fever, jaundice, vomiting, hematemesis and melena. She never got admitted into the hospital in the past. She was immunized as per national immunization schedule and her milestones of development were age proportional. The patient is the first child of non-consanguineous parents, with normal per vaginal delivery and her only other sister who is one year of age is apparently normal. There were no signs and symptoms of mental retardation and her neurological functions were intact. She did not receive any blood transfusion. As her father has been serving in Chittagong as a vehicle driver, so the whole family was residing in Chittagong though their permanent residence is in Lalmonirhat (NorthWest part of Bangladesh).

On examination in the child outpatient Department, the patient was found moderately anemic and had massive hepatosplenomegaly. There were no stigmata of chronic liver disease. Examination of the alimentary system revealed non-tender distended abdomen. Liver was palpable about eight centimeters from the right costal margin in mid clavicular line. Spleen was also palpable about $18 \mathrm{~cm}$ from the left costal margin in mid clavicular line. Both liver and spleen were non-tender, firm in consistency and have smooth surface with regular margin. There were no evidences of ascities. No abnormality was detected on examination of the cardiovascular, respiratory, nervous and musculoskeletal systems. The attending physician advised to get her admitted into the children ward for further management. In the child ward, patient and her parents were thoroughly interviewed and the child was re-examined. The indoor physician ordered initial routine investigations such as complete blood count, peripheral blood film examination, malaria parasite, immuno-chromatographic test for malaria, random blood sugar, liver function tests, urine routine and microscopic examination. After getting the results of all investigations, child specialists sat together, reviewed her history, physical findings and the results of all investigations so far received, discussed the case in details and decided to refer the patient to a tertiary care military hospital at Dhaka for further evaluation, proper diagnosis and management.

In mid June 2015, the patient got admitted into the child ward of a tertiary care military hospital, Dhaka. The attending child specialist re-examined the patient and reviewed all the investigations performed in Chittagong from where the case was referred. The pediatrician also advised to repeat all the investigations so far done and added some other investigations such as immunochromatographic test for Kalaazar, Mantoux test, serum lipid profile, serum iron profile, hemoglobin electrophoresis, X-ray chest (P/A view), skull (A/P and lateral view), knee joint $(\mathrm{A} / \mathrm{P}$ and lateral view), ultrasonography and computed tomography of whole abdomen and bone marrow examination. On the basis of history, physical findings and investigations done at Chittagong, a provisional diagnosis was made.

\section{Provisional Diagnosis \\ Hereditary hemolytic anemia}

\section{Differential Diagnosis}

Dr Mohammad Mizanur Rahman: This 7 year old child had a history of anorexia, weight loss, generalized weakness, gradual distension of the abdomen, moderate anemia and long standing painless massive hepatosplenomegaly. These 


\begin{tabular}{|c|c|c|}
\hline \multicolumn{3}{|c|}{ Table I } \\
\hline \multicolumn{3}{|c|}{ Laboratory data } \\
\hline Variable & $\begin{array}{c}\text { Reference range, } \\
\text { Children (6-12 years) }\end{array}$ & $\begin{array}{c}\text { In the children ward, } \\
\text { Dhaka }\end{array}$ \\
\hline Hemoglobin $(\mathrm{g} / \mathrm{dL})$ & $11.5-15.5$ & 7.4 \\
\hline Hematocrit (L/L) & $0.4-0.5$ & 0.2 \\
\hline $\operatorname{RBC}\left(\times 10^{12} / \mathrm{L}\right)$ & $4.0-5.2$ & 2.5 \\
\hline Mean cell volume (fl) & $77-95$ & 69 \\
\hline White cell count $\left(\times 10^{9} / \mathrm{L}\right)$ & $5.0-13.0$ & 2.2 \\
\hline \multicolumn{3}{|l|}{ Differential count (\%) } \\
\hline Neutrophils & 53 & 44 \\
\hline Lymphocytes & 39 & 47 \\
\hline Monocytes & 04 & 04 \\
\hline Eosinophils & 02 & 05 \\
\hline Basophils & $<1-2$ & 00 \\
\hline Blasts & 00 & 00 \\
\hline Platelet count (x109/L) & $170-450$ & 65 \\
\hline Peripheral blood film & & Pancytopenia \\
\hline ICT for malaria & & Negative \\
\hline ICT for Kala-azar & & Negative \\
\hline Liver function tests & & Normal \\
\hline Random plasma sugar & & $5.3 \mathrm{mmol} / \mathrm{L}$ \\
\hline Urine $\mathrm{R} / \mathrm{M} / \mathrm{E}$ & & Normal \\
\hline Mantoux test & & Negative \\
\hline Serum lipid profile & & $\begin{array}{l}\text { High serum triglycer- } \\
\text { ide }(193 \mathrm{mg} / \mathrm{dL}) \text {; } \\
\text { low serum cholesterol }\end{array}$ \\
\hline Serum iron profile & & Normal \\
\hline $\mathrm{Hb}$ electrophoresis & & Normal \\
\hline Bone marrow study & & $\begin{array}{l}\text { Suggestive of Gaucher } \\
\text { disease }\end{array}$ \\
\hline \multicolumn{3}{|c|}{$\begin{array}{l}\text { I Reference values are affected by many variables, including the demographics and the } \\
\text { laboratory methods used. The ranges used at the Armed Forces Institute of Pathology } \\
\text { (AFIP) are for children (6-12 years) who do not have medical conditions that could affect } \\
\text { the results. They may, therefore, not be appropriate for all patients }\end{array}$} \\
\hline
\end{tabular}

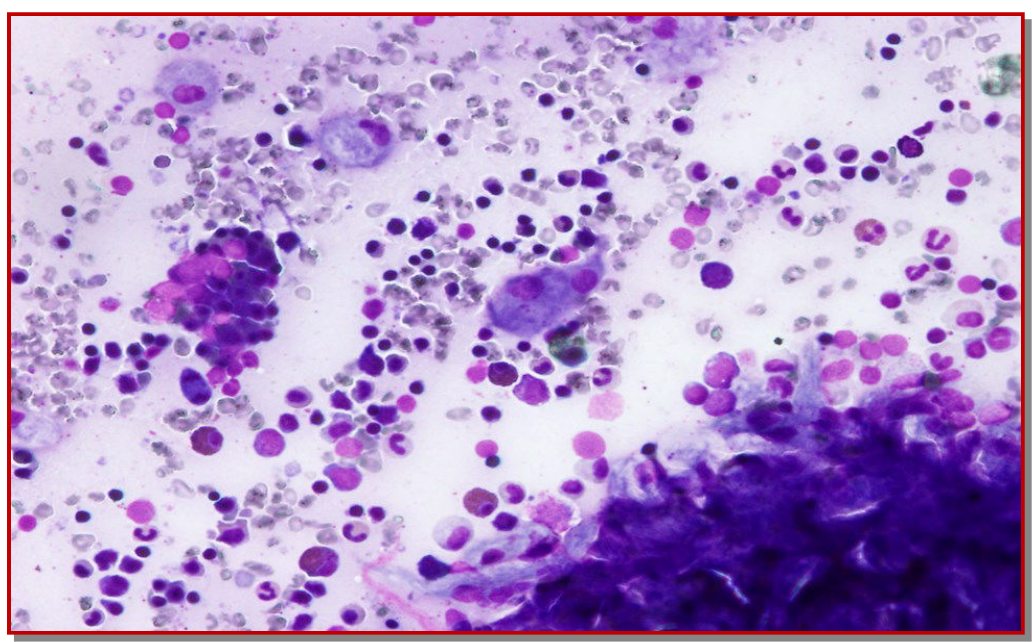

Figure 1: Leishman stained bone marrow slide showing Gaucher cell (indicated by arrow) findings are relatively common in such a child in Bangladesh and there are several differential diagnoses. However, findings such feature in a child of this age particularly in Bangladesh and Indian Subcontinent can help to narrow the list of the possible causes. Therefore, I will first focus on my differential diagnosis.

\section{Tropical splenomegaly syndrome}

Tropical splenomegaly syndrome, also known as hyper-reactive malarial syndrome, occurs due to frequent assault of malaria infection over a long period leading to immunological over stimulation. 1 This condition is most prevalent in many malarious zones of the tropics including Uganda, Nigeria, New guinea and Congo as well as Indian subcontinent.2 Tropical splenomegaly syndrome is described by massive splenomegaly, hepatomegaly, marked elevations in serum IgM levels (more than 1000 IU/ $\mathrm{mL}$ ), antimalarial antibodies and a good clinical response to antimalarial therapy with regression of splenomegaly, elevation of hemoglobin level and decreasing serum IgM level. $\underline{-}$ Tropical splenomegaly syndrome is not the result of active malarial infection, though it appears that malaria is primarily responsible for tropical splenomegaly syndrome. A peripheral smear for malaria parasite is usually negative and the malarial pigment is not found in the biopsy material from the liver and spleen. The continual presence of malarial antigen leads to an aberrant host response resulting in a reactive and relatively benign lymphoproliferative disorder that affects the liver and spleen, seems more likely to be the pathogenesis of tropical splenomegaly syndrome. 4 The condition may show the characters of severe hypersplenism including anemia and thrombocytopenia. 5 As the patient presented with long standing painless massive hepatosplenomegaly and moderate anemia, these features are, therefore, suggestive of tropical splenomegaly syndrome but no past history of malaria as well as not residing in the malarial hyperendemic zone disfavors the diagnosis of tropical splenomegaly syndrome.

\section{Chronic visceral Leishmaniasis}

Leishmaniasis is a parasitic disease caused by Leishmania donovani complex (comprising $L$. donovani, $L$. infantum, L. chagasi) that spread to people through the bite of the female phlebotomine sandfly. 6 Leishmania infection in human is caused by more than 20 species of Leishmania. The risk factors which may predispose to such infections include: Poverty, malnutrition, deforestation and urbanization. 7 In about 98 countries, 4 to 12 million people are infected and two million new cases are infected each year. Between 20 and 50 thousand deaths occur in every year. About 200 million people are residing in areas such as Asia, Africa, south and central America and southern Europe where leishmaniasis is common. 8 More than $90 \%$ of the World's cases of visceral leishmaniasis are in India, 


\begin{tabular}{|cl|}
\hline \multicolumn{2}{|c|}{ Table II } \\
\hline \multicolumn{2}{|c|}{ Report of enzyme assay } \\
\hline Beta-glucocerebrosidase value (nmol/hour/mg) & Remarks \\
\hline$>4$ & Normal activity \\
$2-4$ & Possibility of carrier \\
$<2$ & Deficient activity \\
Patient value & 0.56 nmol/hour/mg \\
\hline
\end{tabular}

Bangladesh, Nepal, Sudan, and Brazil.9 Visceral leishmaniasis, which is usually caused by $L$. donovani, is the most serious form and potentially fatal if untreated and is characterized by fever, massive splenomegaly, hepatomegaly and anemia.10 Visceral leishmaniasis is diagnosed in the hematology laboratory by direct visualization of LD body in aspirates from the bone marrow, spleen and lymph nodes. 11 In this case, moderate anemia and massive hepatosplenomegaly favor the diagnosis of chronic visceral leishmaniasis but absence of fever, anorexia and residing in an area where leishmaniasis is uncommon are the features against visceral leishmaniasis.

\section{Chronic liver disease}

Chronic liver disease is the disease of the liver lasting over a period of six months characterized by progressive destruction and regeneration of liver parenchyma resulting in fibrosis, cirrhosis and in some cases hepatocellular carcinoma.12 In day to day clinical practice in Bangladesh, patients with chronic liver disease is commonly encountered. No age is immune for chronic liver disease and often causes prolonged morbidity and is an important cause of premature death. $\underline{\underline{13}}$ There are many conditions and causes of chronic liver disease, among which hepatitis $B$ and hepatitis $C$ virus are the most important etiological factors. Besides these, non-alcoholic hepatic steatosis and autoimmune hepatitis also contribute to the development of chronic liver disease.14 Patients with chronic liver disease clinically may present with ascities, features of hypersplenism with or without splenomegaly, anemia, jaundice, bleeding manifestations and other stigmata of chronic liver disease (palmar erythema, nail clubbing, spider nevi)..$\underline{15}$ Moderate anemia and splenomegaly are in favor of chronic liver disease but massive hepatomegaly, absence of ascities, jaundice and stigmata of chronic liver disease oppose the diagnosis of chronic liver disease.

\section{Chronic myeloid leukemia}

Chronic myeloid leukemia is a clonal stem cell myeloproliferative disorder almost exclusively occurring in adults with peak incidence in between 40 and 60 years of age. It is characterized by a proliferation of myeloid cells of all stages of differentiation and the $t$ (9:22) (q34:q:11) leading to formation of BCR-ABL fusion gene. Chronic myeloid leukemia is uncommon in childhood, accounting for only 2 to $5 \%$ of all leukemias. It has incidence of $<1$ case per $1,00,000$ population younger than 20 years of age per year.16 Chronic myeloid leukemia accounts less than $10 \%$ of all leukemias under the age of 20 years and $7-20 \%$ of all leukemias seen at all ages. After the age of 60 years it is very rare and occasionally occurs in children. .17 About 50 years ago, two forms of chronic myeloid leukemia were described in children. One had the typical features of chronic myeloid leukemia of adulthood and appeared in children after the age of 4 years; the another type affected children in between 1 and 4 years of age and presented as myelomonocytic proliferation associated with hemorrhage, infection, lymphadenopathy and skin rash. The prognosis of the later group is invariably poor.18 The hallmark of juvenile type chronic myeloid leukemia is the absence of Philadelphia chromosome. Philadelphia chromosome is rarely seen in children. 19,20 Chronic myeloid leukemia is divided into three phases: Chronic, accelerated and blast phase. Approximately $85 \%$ of patients with chronic myeloid leukemia are in chronic phase at the time of diagnosis. During chronic phase patient may be completely asymptomatic or may have hypermetabolic symptoms such as fatigue, increased sweating and loss of appetite, weight loss and sometimes with features indicative of hepatosplenomegaly. 11,22 Massive splenomegaly, weight loss and the presence of moderate anemia in this patient was in favor of the diagnosis of chronic myeloid leukemia but age of the patient, hepatomegaly and absence of hyper-metabolic symptoms were the features against the diagnosis of chronic myeloid leukemia.

\section{Lysosomal storage diseases}

Lysosomal storage diseases are genetically inherited metabolic disorders resulting from defects in lysosomal function usually as a consequence of deficiency of a single enzyme required for the metabolism of lipids, glycoproteins or mucopolysaccharides. Individually lysosomal storage diseases occur with incidences of less than 1:100,000. However, as a group the incidence is 1:5,000-1: 10,000. Most of the lysosomal storage diseases are usually inherited in autosomal recessive fashion and results from different gene mutations that translate into a deficiency of enzyme activity and therefore they all share common biochemical characteristic- an abnormal accumulation of substances within the lysosome. The lysosomal storage diseases are generally classified by the nature of the primary stored material involved and can be broadly broken into lipid storage disorders (such as Gaucher disease, Niemann Pick disease), mucopolysaccharidoses (Hunter and Hurler syndrome), glycogen 
storage disorders (Pompe disease) and mucolipidoses. 23,24 Lysosomal storage diseases affect mostly children and they often die at younger and unpredictable age. The symptoms of lysosomal storage disease vary, depending on the particular disorder and other variables like the age of onset, and can be mild to severe. They can include developmental delay, movement disorders, seizures, dementia, deafness and/or blindness. Some people with lysosomal storage disease have massive hepatosplenomegaly, pulmonary and cardiac problems and bones that grow abnormally. $\underline{25}$ Gaucher and Niemann Pick diseases are the most important cause of massive hepatosplenomegaly in children. As this patient presented with long standing painless massive hepatosplenomegaly, moderate anemia without fever, no past history of malaria as well as no neurodegenerative regression and involvement of musculoskeletal system, among the lysosomal storage diseases, Gaucher disease is the most likely diagnosis.

Dr. Mahbuba Sultana: After two days I got the results of the laboratory and radiological investigations which were sent after getting admitted into the military hospital, Dhaka. The results of the laboratory investigations are shown in Table I. Radiological and imaging investigations revealed normal chest skiagram and X-ray of the skull and knee were normal. Ultrasonogram and computed tomography of the whole abdomen showed moderately enlarged liver and hugely enlarged spleen. Bone marrow examination depicted a hypercellular marrow with increased M:E ratio. Erythropoiesis and granulopoiesis were depressed. Megakaryocytes were normal. Marrow is heavily infiltrated with numerous large cells having fibrillary cytoplasm morphologically resemble Gaucher cell (Figure 1). Bone marrow examination was carried out by Dr. Rahman who also informed that the bone marrow aspirate was also stained with Periodic Acid Schiff (PAS) stain which gave strong positivity suggesting the diagnosis of Gaucher disease. Dr. Rahman also gave advice to perform leucocyte acid beta-glucocerebrosidase assay, DNA analysis for GBA gene, plasma chitotriosidase assay and serum ferritin and lipid profile measurement. To confirm the diagnosis of Gaucher disease, I sent the patient's blood sample overseas for the estimation of leucocyte acid beta-glucocerebrosidase assay. After two weeks I received the result of enzyme assay which was markedly diminished $(0.56 \mathrm{nmol} /$ hour/ $\mathrm{mg}$ ) and shown in Table II, confirming the diagnosis of Gaucher disease.

\section{Dr. Shourov's Diagnosis}

Gaucher disease

\section{Discussion}

Dr. Rahman: It is now an established and settled issue that Gaucher disease is a genetic disorder. Genetic disorders in children are not that rare anymore, almost in every block on every street we see syndromic child with some form of genetic disorders. Many of the general people don't understand the reason behind their unusual appearance and behavior. Also most people thought that genetic studies are dead end investigations with no possible treatment. But this is not fact as the treatment is available for some genetic diseases such as Gaucher disease, Pompe disease, Hurler syndrome, Febry disease, Hunter syndrome, mucoplosaccharidoses type VI and Niemann Pick disease, type I. 26

About 1 in 100 people in the United States are carriers of the gene for type I Gaucher disease which is the most common type. The month October marks as the National Gaucher's Disease Awareness month in the United States.27

Each type of Guacher disease has been linked to the particular mutations. There are about 80 known mutations, grouped into three main types. N370S homozygote is responsible for type I Gaucher disease, also called the "non-neuropathic" type and occurs mainly in Ashkenazi Jews, about 100 times the occurrence in the general population. The median age at diagnosis is 28 years of age and the life expectancy is mildly decreased. Type II (one or two alleles L444P) is characterized by neurological problems among small children. The enzyme is hardly released into the lysosomes. The prognosis is poor. Most of them die before the age of three. Type III (also one or two copies of L444P, possibly delayed by protective polymorphisms) occurs in Swedish patients. This group develops the disease somewhat later, but most of them die before their 30th birthday. .28

Gaucher disease is suggested based on the overall clinical picture which was present in this patient. Initial screening test is serum chitotriosidase. This enzyme assay is simple. The enzyme chitotriosidase has proved to be very useful for screening as well as monitoring Gaucher's disease activity in response to treatment and may reflect the severity of the disease. Next laboratory test include glucocerebrosidase enzyme assay. Decreased enzyme levels in the leucocytes is often confirmed by genetic testing. As there are numerous different mutations, sequencing of the beta-glucosidase gene is sometimes necessary to confirm the diagnosis. Prenatal diagnosis is available and is useful when there is a known genetic risk factor. A diagnosis can also be supported by the biochemical abnormalities such as high alkaline phosphatase, angiotensin-converting enzyme, serum triglyceride and serum ferritin 
and immunoglobulin level as well as low serum cholesterol or by cell analysis showing "crinkled paper" cytoplasm and glycolipid-laden macrophages on $\mathrm{H}$ and $\mathrm{E}$ staining. .99

I would like to inform that from January 2016 to July 2017, two cases were diagnosed as Guacher disease by morphological examination of bone marrow aspirate at the Armed Forces Institute of Pathology (AFIP), Dhaka cantonment, Bangladesh.

Dr. Abdul Ali Miah: Enzyme replacement therapy is now available and if the enzyme is given intravenously, it can dramatically decrease the liver and spleen size, reduce the skeletal abnormalities and reverse other manifestations but the cost is very high. Due to low incidence of the disease, this drug has become an orphan drug in many countries. $\underline{30}$

Dr. S. M. Motahar Hossain: The incidence of type I Gaucher disease is gradually increasing, giving a prevalence of one in 40,000. Among Ashkenazi Jews, the rate of carriers is considerably higher, at roughly one in 15. Type I Gaucher disease is most common and its prognosis is also good if ERT can be given. However, successful bone marrow transplantation in the treatment of Gaucher disease may cure the disease but the procedure carries significant risk and is now rarely considered in the treatment of Gaucher disease. .11

Dr. Mehedi (Trainee in Surgery): What is the pathogenesis of bone deformity in Gaucher disease?

Dr. Shourov: Progressive infiltration of Gaucher cells in bone marrow results in thinning of the cortex, pathological fracture, bone pain, bone infarct and osteopenia. These bony changes may result in Erlenmeyer flask deformity of the distal femur. $\underline{32}$

Dr. Asfaque (Trainee in Surgery): What is the fate of the patient with Gaucher disease if untreated?

Dr Md. Monirul Islam: If remain untreated, patient gradually develops bone marrow failure, pulmonary disease and nephropathy or glomerulonephritis which may lead to death. $\underline{32}$

Dr Manun Mostafe: What is the mechanism of development of anemia?

Dr Rahman: Increased pooling and flow-induced dilutional anemia are the main pathological factors responsible for anemia in patients with Gaucher disease. Besides these, anemia may be due to bone marrow infiltration by Gaucher cell, bone marrow suppression by cytokines released in Gaucher disease as well as hypersplenism. $\underline{33}$

Dr. Miah: Why type II and type III are more serious than type I Gaucher disease?

Dr Rahman: The amount of residual enzyme (betaglucocerebrosidase) activity determines the disease subtype and severity. In type II and III Gaucher disease, the mutations responsible for this type of disease express the very low level of enzyme activity. $\underline{32}$

Dr. Hossain: Did this patient develop hypersplenism?

Dr. Mohammad Shahidul Islam: This patient develops the features of secondary hypersplenism such as pancytopenia, massive splenomegaly and hypercellular bone marrow.

Dr. Haque Mahfuz: Why didn't you include juvenile chronic myeloid leukemia as one of the differential diagnosis?

Dr. Shourov: I have included chronic myeloid leukemia as one of the differential diagnosis. Juvenile chronic myeloid leukemia is an old term which was described about 50 years ago. Now the term Juvenile chronic myelomonocytic leukemia is used. ${ }^{18}$

Dr. Mahfuz: Should we consider bone marrow transplantation as one of the effective mode of treatment?

Dr. Lutfunnahar Khan: Successful bone marrow transplantation cures the non-neurological manifestation of the disease as it introduces monocyte population with active beta-glucosidase activity. But the procedure carries significant risk and is rarely performed in Gaucher disease. $\underline{31}$

Dr. Syed Zoherul Alam: What are the radiological findings you expect in Gaucher disease?

Dr. Rahman: Most patients with type I Gaucher disease have radiological evidence of skeletal involvement including an early change, Erlenmeyer flask deformity of the distal femur. In patients with symptomatic bone disease, lytic lesions can develop in the long bones, ribs and pelvis and osteosclerosis may be evident at an early age. $\underline{32}$

\section{Final Diagnosis}

Gaucher disease

\section{References}

1. Fakunle YM. Tropical splenomegaly. Clin Hematol Trop Areas. 1981; 10: 963-81.

2. Neelam R, Neela S, Vani SN. Tropical splenomegaly syndrome. Indian J Pediatr. 1991; 58: 67981.

3. Hamilton PJS. Disorders of hemopoietic system: The spleen. In: Diseases of children in the subtropics and tropics. Jelliffe DB, Stanfield JP (eds). 3rd ed. London, Edward Arnold Publishers, 1979, pp 601-04. 
4. Hoffbrand AV, Moss PA. Hoffbrand's Essential haematology. In: The spleen. Hoffbrand AV, Moss PA (eds). 7th ed. New Delhi, Willey Blackwell, 2016, pp 116-21.

5. Greenwood B, Fakunle Y. The tropical splenomegaly syndrome. In: The role of the spleen in the immunology of parasitic disease. Basel, Schwabe, 1979, pp 229-51.

6. Salma U, Khan AH, Rahman MFU, Irshadullah NM, Shumy F, Chowdhury MAJ. Leishmanial hepatitis with chronic hepatitis B infection treated successfully with liquid form of liposomal amphotericin B: A case report. Bangabandhu Sheikh Mujib Med Univ J. 2012; 5: 55-56.

7. Leishmaniasis fact sheet. World Health Organization, 2014.

8. Barrett MP, Croft SL. Management of trypanosomiasis and leishmaniasis. Bri Med Bull. 2012; 104: 175-96.

9. Visceral leishmaniasis at the wayback machine. Institute of One World Health, 2010.

10. Leishmaniasis magnitude of the problem. World Health Organization, February 2014.

11. Osei-Bimpong A, Burthem J. Supplementary techniques including blood parasite diagnosis. In: Dacie and Lewis Practical hematology. Bain BJ, Bates I, Laffan MA (eds). 12 th ed. Philadelphia, Churchill Livingstone/Elsevier, 2017, pp 93-111.

12. Laleman W, Verbeke L, Meersseman P: Acute-onchronic liver failure: Current concepts on definetion, pathogenesis, clinical manifestations and potential therapeutic interventions. Expert Rev Gastroenterol Hepatol. 2011; 5: 523.

13. Hossain SF, Islam QT, Siddiqu MR, Hossain A, Jahan N. A study of hypoalbuminaemia in chronic Liver disease and its correlation with development of esophageal varices. Bangladesh J Med. 2011; 22: 17-20.

14. Chung RT, Baumert TF. Curing chronic hepatitis C: The arc of medical triumph. N Engl J Med. 2014; 370: 1576.

15. Theise ND. Liver and gall bladder. In: Robbins and Cotran Pathologic basis of disease. Kumar V, Abbas AK, Aster JC (eds). 9th ed. Philadelphia, Elsevier Saunders, 2015, pp 825-35.

16. Hossain HT, Islam QT, Adnan MMBMS, Khandaker MA. Adult type chronic myeloid leukemia in an 11 years old girl: A very unusual case report. Bangladesh J Med. 2014; 25: 72-75.

17. Shittu AO, Babatunde AS, Adewoye AO. Clinicopathological features of chronic myeloid leukemia at diagnosis: Study of a series of 46 cases. Bangladesh J Med Sci. 2016; 15: 20-24.

18. Bernard J, Mathe G, Delorme JC, Barnoud O. La leucemiemyeloide chronique de l'enfant. Arch Fr Pediatr. 1962; 19: 881.
19. Reisman LE, Trujillo JM. Chronic granulocytic leukemia of childhood: Clinical and cytogenetic studies. J Pediatr. 1962; 62: 710.

20. Sinniah Daraffin WA, Shiong HW, Lin HP. Chronic myeloid leukemia in Malaysian children. Singapore Med J. 1981; 22: 350-53.

21. Tefferi A. Classification, diagnosis and management of myeloproliferative disorders in the JAK2V617F era. Hematology/the Education Program of the American Society of Hematology. American Society of Hematology. Education Program, 2006, pp 240-45.

22. Savage DG, Szydlo RM, Goldman JM. Clinical features at diagnosis in 430 patients with chronic myeloid leukaemia seen at a referral centre over a 16 years period. Bri J Haematol. 1997; 96: 111-16.

23. Winchester B, Vellodi A, Young E. The molecular basis of lysosomal storage diseases and their treatment. Biochem Soc Trans. 2000; 28: 150-54.

24. Meikle PJ, Hopwood JJ, Clague AE, Carey WF. Prevalence of lysosomal storage disorders. JAMA. 1999; 281: 249-54.

25. Back M. New therapeutic options for lysosomal storage disorders: Enzyme replacement, small molecules and gene therapy. Hum Genet. 2007; 121: $1-22$.

26. Purandare H, Chakravarty A. Human cytogenetic techniques and clinical applications. Mumbai, Bhalani Publishing House, 2000; 2-10.

27. Zimran A, Gelbart T, Westwood B, Grabowski GA, Beutler E. High frequency of the Gaucher disease mutation at nucleotide 1226 among Ashkenazi Jews. Am J Hum Genet. 1991; 49: 855-59.

28. Nagral A. Gaucher disease. J Clin Exp Hepatol. 2014; 4: 37-50.

29. Dandana A, Khelifa B, Chahed S, Abdelhédi FS. Gaucher disease: Clinical, biological and therapeutic aspects. Pathobiology 2016; 83: 13-23.

30. Brady RO, Kanfer JN, Shapiro D. Metabolism of glucosylceramidase II: Evidence of an enzymatic deficiency in Gaucher's disease. Biochem Biophys Res Commun. 1965; 18: 221-25.

31. Grabowski GA. Phenotype, diagnosis, and treatment of Gaucher's disease. Lancet 2008; 372: 126371.

32. McGovern MM, Desnick RJ. Abnormalities of the monocyte-macrophage system: The lysosomal storage diseases. In: Wintrobe's Clinical hematology. Lee GR, Foerster J, Lukens J, Paraskevas F, Greer JP, Rodgers GM (eds). 10 $10^{\text {th }}$ ed. Philadelphia. Williams \& Wilkins. 1999, pp 1908-15.

33. Sheldon GF, Croom RD III, Meyer AA. The spleen. In: Textbook of surgery. Sabiston DC (ed). 14th $\mathrm{ed}$. Philadelphia, WB Saunders, 1991, pp 1108-13. 